\title{
Construção e validação da Escala de Crenças Parentais e Práticas de Cuidado (E-CPPC) na primeira infância
}

\author{
Gabriela Dal Forno Martins - Universidade Federal de Santa Catarina, Florianópolis, Brasil \\ Samira Mafioletti Macarini - Universidade Federal de Santa Catarina, Florianópolis, Brasil \\ Mauro Luís Vieira ${ }^{-}$- Universidade Federal de Santa Catarina, Florianópolis, Brasil \\ Maria Lúcia Seidl-de-Moura - Universidade do Estado do Rio de Janeiro, Rio de Janeiro, Brasil \\ Vera Silvia Raad Bussab - Universidade de São Paulo, São Paulo, Brasil \\ Roberto Moraes Cruz - Universidade Federal de Santa Catarina, Florianópolis, Brasil
}

\begin{abstract}
Resumo
O presente estudo teve como objetivo construir e validar uma escala de crenças parentais e práticas de cuidado na primeira infância para o contexto brasileiro. Após a construção teórica dos itens, a versão final da escala foi aplicada em dois estudos com populações distintas (estudo preliminar - 250 mães; estudo final - 600 mães), visando avaliar a frequência de comportamento e o grau de importância atribuído às práticas. Para as análises psicométricas, foram realizadas: análise fatorial e o cálculo da consistência interna. Em ambos os estudos a análise fatorial resultou em dois fatores, sendo o primeiro denominado "cuidados primários" e o segundo "estimulação". Os alfas de Cronbach apresentaram-se satisfatórios, variando de 0,68 a 0,83. Os resultados do estudo demonstraram a validade e precisão da escala, a qual poderá ser utilizada em futuras pesquisas, bem como em práticas de intervenção familiar, principalmente durante os primeiros anos de vida das crianças.

Palavras-chave: Crenças parentais, Práticas de cuidado, Escala.
\end{abstract}

\section{Construction and validation of the Parenting Beliefs and Caring Practices Scale for the early childhood}

\begin{abstract}
This study aimed to develop and validate a scale of parenting beliefs and caring practices in the early childhood in Brazilian contexts. After the theoretical construction of items, the final version of the scale was administered in two studies with different samples of mothers (preliminary study $\mathrm{N}=250$; final study $\mathrm{N}=600$ ), assessing the frequency of each behavior and the degree of importance attributed to the practices. The psychometric analyses used for the validation of the scale were: factorial analysis and calculation of internal consistency. In both studies, the factorial analysis resulted in two factors: the first was called "primary care" and the second "stimulation". The Cronbach's coefficient properties were satisfactory, ranging from .68 to .83. The results demonstrated the validity and reliability of the scale, which can be used for future studies and intervention practices with families, especially during children's early years.

Keywords: Parenting beliefs, Caring practices, Scale.
\end{abstract}

O conjunto de relações estabelecidas entre pais e filhos é permeado por necessidades distintas, porém complementares, como o cuidado, a educação e a promoção do desenvolvimento infantil. Tais imperativos resultam em um conjunto característico de comportamentos ou práticas, que em geral são nomeadas de diferentes formas na literatura, como por exemplo: práticas de cuidados, cuidados parentais, práticas parentais, práticas educativas e estilos parentais. Estão presentes também termos referentes às cognições parentais, como crenças, idéias e valores parentais.

\footnotetext{
1 Endereço para correspondência:

Departamento de Psicologia da Universidade Federal de Santa Catarina - Campus Universitário

Trindade - 88040-900 - Florianópolis - SC

E-mail: maurolvieira@gmail.com
}

A diversidade de conceitos utilizados parece fornecer indícios da coexistência de diferentes concepções sobre a parentalidade humana em momentos distintos do ciclo vital. Além disso, verificam-se, pelo menos, duas grandes dimensões: o que os pais fazem (comportamentos ou práticas) e o que os pais pensam (cognições) durante a criação dos filhos.

Para o presente estudo, será utilizado um modelo de entendimento da parentalidade proposto por Keller (2002; 2007), o qual engloba tanto as práticas de cuidado utilizadas por pais de crianças de até três anos de idade quanto as crenças que os mesmos possuem e que orientam seus comportamentos. A autora tem investido na fase inicial do desenvolvimento por dois principais motivos. O primeiro deles é teórico, já que o estudo da interação do bebê com seus cuidadores possibilita a compreensão da interação entre a 
biologia e a cultura. O segundo motivo é prático, uma vez que o estudo voltado para pais e bebês pode embasar intervenções precoces visando à promoção do desenvolvimento da criança e da família como um todo. Nesse sentido, trabalhar com relações iniciais cuidador-criança trata-se de uma forma de atuar na prevenção e promoção da saúde e desenvolvimento, pois os padrões de relação ainda estão sendo estabelecidos.

Keller (2002; 2007) criou um modelo teórico para compreensão da parentalidade, buscando integrar as diferentes facetas desse fenômeno. Os cuidados que os pais dispensam à criança são compreendidos por meio de um "Modelo de Componentes da Parentalidade", composto de seis sistemas parentais e três mecanismos interacionais, os quais são definidos por uma série de comportamentos geneticamente preparados e ativados pelas demandas do ambiente, com o objetivo de reduzir o desconforto quando a criança está em risco real ou potencial.

Os seis sistemas parentais propostos por Keller $(2002$; 2007) são os seguintes:

1) Cuidado primário - é filogeneticamente o sistema de cuidados mais antigo e visa prover alimentos, proteção e higiene à criança. Sua função psicológica caracteriza-se pela redução do desconforto no bebê. Além disso, a criança desenvolve confiança e segurança na proteção e disponibilidade do cuidador como dimensões primárias do self emergente;

2) Contato corporal - é o contato corpo a corpo e o carregar extensivo, envolvendo também o dormir junto. A função psicológica desse sistema consiste na experiência de calor emocional, garantindo ao bebê os sentimentos de coesão social e pertencimento ao grupo. $O$ calor emocional contribui para que a criança aceite as regras e valores dos pais, preparando-a para uma vida baseada na harmonia e hierarquia entre os membros da família ou do grupo social primário;

3) Estimulação corporal - visa a comunicação corporal por meio do toque e movimentos motores. Sua função psicológica consiste em intensificar a percepção do bebê com relação a seu próprio corpo e ao ambiente circundante e, consequentemente, a promoção de um self corporal próprio;

4) Estimulação por objetos - pela utilização de brinquedos na interação cuidador-criança, visa vincular o bebê ao mundo dos objetos e ao ambiente físico em geral. Nesse sistema a utilização de objeto pode substituir a presença do adulto, estando também intimamente relacionado a atividades exploratórias. Sua função psicológica consiste em promover o desenvolvimento cognitivo, bem como tornar a criança mais independente de relações sociais;

5) Contato face a face - consiste no contato visual mútuo entre cuidador e bebê, em que o investimento parental é diádico e exclusivo. As trocas face a face são altamente estimulantes, carregadas de afeto e constituem-se de curtos eventos interacionais que expõem a criança a altos níveis de informação cognitiva e social. Mediante esse sistema de trocas, a criança nota contingências em que a prontidão das respostas do adulto faz com que ela se perceba como causa do comportamento parental. Além disso, também se torna consciente de que é um ser único e autoeficaz. Esse sistema ainda é capaz de facilitar o desenvolvimento do diálogo verbal e a promoção da capacidade de autorregulação da criança.

6) Envelope narrativo - consiste na utilização $\mathrm{da}$ linguagem por parte dos cuidadores, pelo conversar com a criança, auxiliando na apropriação cultural da concepção de self e do outro. É muito influenciado pelo estilo narrativo da mãe ao se comunicar com o bebê, o qual é influenciado pelo modelo cultural em que ela se insere.

Resultados de estudos empíricos realizados por Keller e seus colaboradores (Keller, Yovsi, Borke, Jensen \& Papaligoura, 2004; Keller, Borke, Yovsi, Lohaus \& Jensen, 2005; Keller, Kuensemueller \& cols., 2005; Keller, 2007) têm encontrado predominantemente a existência de dois estilos parentais, denominados distal e proximal. No estilo distal, a estratégia parental focaliza-se nos sistemas de contato face a face e na interação por objetos, propiciando à criança uma experiência de autonomia e separação. $O$ estilo proximal, por sua vez, é caracterizado pelo contato e estimulação corporal, garantindo à criança uma relação interpessoal próxima e calorosa.

\section{Medidas referentes à parentalidade: tendências nacionais}

Iniciativas no sentido de mensurar os diferentes aspectos da parentalidade vêm sendo desenvolvidas, com alguns instrumentos construídos ou validados para a utilização no Brasil. Neste contexto, a primazia de estudos sobre o tema envolve principalmente os conceitos de práticas educativas e estilos parentais tendo como foco o período da adolescência (Martins, Macarini, Minetto \& Vieira, no prelo). Este dado 
possivelmente tem relação com o fato de haver maior facilidade de acesso às práticas mediante do discurso dos adolescentes, os quais são capazes de responder a instrumentos como questionários e entrevistas. Assim, verifica-se uma lacuna na literatura brasileira de estudos que focalizem as práticas parentais na primeira infância, bem como de instrumentos fidedignos que possam ser utilizados para esta investigação.

Os dois instrumentos mais utilizados no Brasil são o Inventário de Estilos Parentais - IEP (Gomide, 2006) e as escalas de Exigência e Responsividade (Costa, Teixeira, \& Gomes, 2000), ambos para investigar as práticas educativas e o estilo parental de pais de adolescentes. Para avaliar as atitudes parentais diante das crianças em idade pré-escolar e escolar, um instrumento traduzido, adaptado e validado para o contexto brasileiro é o Parental Attitude Research Instrument - PARI. O mesmo foi construído originalmente por Schaeffer e Bell (1958), constituído de 115 itens que compõem 23 subescalas organizadas em três fatores: autoritarismo-controle, hostilidaderejeição e democracia-igualitarismo. Ainda, um instrumento construído no Brasil, também relacionado às práticas educativas, porém voltado a pais de filhos entre 6 e 10 anos de idade, é o Inventário de Práticas Parentais - IPP (Benetti \& Balbinotti, 2003). O mesmo é composto de quatro dimensões, das quais apenas duas com alfa de Cronbach satisfatórios: afeto $(0,76)$, educação $(0,82)$, disciplina $(0,55)$ e social $(0,58)$. Este instrumento ainda é pouco utilizado por existirem poucos estudos que demonstrem suas propriedades psicométricas.

Por fim, vale mencionar um estudo recente de Vieira e colaboradores (no prelo), que realizaram uma validação para o contexto brasileiro da Escala de Crenças Sobre Práticas Parentais na primeira infância, originalmente construída por Suizzo (2002). Participaram da validação 350 mães brasileiras, residentes em sete cidades das cinco regiões do país. A análise fatorial confirmou a presença dos três fatores obtidos no estudo original: (1) Apresentação apropriada - o qual é composto de itens associados à limpeza e ao bom comportamento da criança em público $(\alpha=0,70)$; (2) Estimulação e exposição a diferentes estímulos - relacionado à importância de garantir à criança estimulações variadas como interações diádicas e grupais, com brinquedos, pela utilização da linguagem e sentidos $(\alpha=0,70)$; Responsividade e Vínculo - relacionado às respostas contingentes dos cuidadores ante as necessidade da criança, bem como a um vínculo de proximidade e proteção $(\alpha=0,60)$.

Os estudos de construção e validação de instrumentos para avaliação da parentalidade no contexto brasileiro demonstram o interesse em relação ao construto, assim como sua aplicação para melhor compreensão e intervenção nos processos psicológicos. No entanto, a literatura ainda indica a presença de alguns problemas metodológicos, como medidas inadequadas do ponto de vista psicométrico, como também a existência de poucos instrumentos voltados para a primeira infância.

Diante do exposto, o objetivo do presente estudo consiste em construir e validar um instrumento sobre crenças parentais e práticas de cuidado para o contexto brasileiro. Uma vez que esta pesquisa é parte de um projeto nacional, foi possível contar com a participação de mães residentes em seis estados do Brasil (Pará, Bahia, Espírito Santo, Rio de Janeiro, São Paulo e Santa Catarina), contemplando, assim, uma diversidade de contextos existentes no país. É importante destacar que o Modelo de Componentes da Parentalidade, utilizado na presente pesquisa, envolve aspectos relacionados à mãe, ao pai e aos cuidadores das crianças. No entanto, como na pesquisa nacional, na qual foram obtidos os dados para a validação, somente as mães foram entrevistadas (tendo em vista a facilidade operacional para contatar com as participantes e pela proximidade com a criança, principalmente na fase inicial do seu desenvolvimento), não foi possível incluir na amostra outros cuidadores. Mesmo assim, considera-se que os resultados poderão ter algum tipo de contribuição para suprir lacuna existente na literatura brasileira, auxiliando na compreensão de alguns aspectos da parentalidade voltada para a primeira infância, descrita através das crenças que as mães possuem sobre a importância de suas práticas de cuidado, bem como por suas práticas de cuidado diárias propriamente ditas.

\section{Método}

Para atingir os objetivos de elaboração e validação da escala sobre crenças parentais e práticas de cuidado foram necessárias três etapas metodológicas distintas: 1) construção teórica dos itens e avaliação da adequação semântica; 2) estudo psicométrico preliminar; e 3) estudo psicométrico final. Os procedimentos realizados 
nessas três etapas permitiram a realização da validade de conteúdo e de construto do instrumento, além da avaliação da precisão e estabilidade do mesmo. A seguir serão apresentados com mais detalhes os procedimentos realizados em cada etapa.

\section{1) Construção teórica dos itens}

A construção dos itens teve como fonte principal o modelo teórico de Keller (2007), que permitiu a definição do construto a ser avaliado: os sistemas parentais. Segundo Pasquali (1998), o passo seguinte à definição do construto trata-se da operacionalização do mesmo mediante a construção de itens na forma de tarefas que as pessoas devem executar para que se possa avaliar a magnitude de presença do construto. Antes da construção dos itens, todavia, alguns procedimentos são necessários para viabilizar um teste com validade de conteúdo (Pasquali, 2003): a) definição do conteúdo; b) explicitação dos processos psicológicos a serem avaliados; e c) determinação da proporção relativa de representação de cada tópico do conteúdo.

Esses procedimentos foram facilitados nesta pesquisa em razão da existência prévia de sistemas categoriais de observação e de conteúdo dos comportamentos e falas das mães em relação aos cinco sistemas parentais em estudos já realizados por Keller e seus colaboradores (Keller, Voelker \& Yovsi, 2005; Keller, Borke \& cols., 2005; Keller \& cols., 2007). Considerou-se que as categorias preexistentes forneciam explicitação suficiente dos processos psicológicos a serem avaliados na escala. Assim, tomando-se como base tais categorias, foram construídos cinco itens para cada dimensão dos sistemas parentais (cuidados primários, contato corporal, estimulação corporal, estimulação por objetos e contato face a face) que expressam respostas da mãe diante de uma criança de até dois anos de idade (Tabela 1).

Tabela 1 - Itens presentes na escala original de crenças parentais e práticas de cuidado

\begin{tabular}{ll}
\hline \multicolumn{1}{c}{ Sistemas Parentais } & \multicolumn{1}{c}{ Itens } \\
\hline \multirow{3}{*}{ Cuidados primários } & 1. Socorrer quando está chorando. \\
& 2. Alimentar. \\
& 3. Manter limpa. \\
& 4. Cuidar para que durma e descanse. \\
& 5. Não deixar que passe frio ou calor. \\
& 6. Carregar no colo. \\
7. Ter sempre por perto. & 8. Abraçar e beijar. \\
& 9. Dormir junto na rede ou cama. \\
& 10. Tentar evitar que se acidente (cuidados de segurança). \\
& 11. Fazer cócegas. \\
& 12. Fazer massagem. \\
& 13. Deixar livre para correr, nadar, trepar. \\
& 14. Brincadeiras de luta, de se embolar (corporais) \\
Estimulação corporal & 15. Fazer atividades físicas. \\
& 16. Jogar brinquedos. \\
& 17. Pendurar brinquedos no berço. \\
& 18. Ver livrinhos juntos. \\
& 19. Mostrar coisas interessantes. \\
Estimulação por objetos & 20. Conversar. \\
& 21. Explicar coisas. \\
& 22. Ouvir o que tem a dizer. \\
& 23. Responder a perguntas. \\
24. Ficar frente a frente, olho no olho.
\end{tabular}

Após a construção dos itens, os mesmos foram apresentados de forma coletiva a pesquisadores que compõem o grupo de pesquisa nacional. Os itens foram lidos e todos puderam avaliar sua pertinência do ponto de vista da dimensionalidade e semântica. A avaliação desse último aspecto levou em conta as diferenças regionais de linguagem, uma vez que os 
pesquisadores eram provenientes de diferentes regiões do Brasil. Para isso foram realizadas submissões a juízes locais, que identificaram expressões não usuais. Em seguida, os itens foram aplicados em pequenas amostras de mães em cada região, na forma de entrevista, e novos ajustes foram feitos quando as mães demonstravam dúvidas sobre o conteúdo de algum item. Por exemplo: no item "brincadeiras de luta" foi incluída a expressão "brincadeira de se embolar, corporal"; no item "dormir na cama", foi incluído "dormir na rede."

\section{2) Estudos psicométricos preliminar e final}

Concluída a etapa de construção e análise teórica dos itens, chegou-se à versão final da Escala de Crenças Parentais e Práticas de Cuidado (E-CPPC). Nessa versão a tarefa das mães consistiu em responder aos itens segundo duas escalas ordinais. Primeiramente, os 25 itens foram apresentados e as mães deveriam avaliá-los quanto a frequência de realização das práticas, segundo uma escala de 5 pontos, que variava de 1 (nunca) até 5 (sempre). Posteriormente, os 25 itens foram novamente apresentados e as mães deveriam avaliá-los quanto ao grau de importância atribuído a cada um deles, segundo uma escala de 5 pontos, que variava de 1 (pouco importante) até 5 (muito importante). Assim, a versão final da escala foi constituída por duas subescalas, denominadas "Práticas Realizadas pela Mãe" (PRM) e "Importância Atribuída às Práticas" (IAP). A escolha pela inclusão das duas subescalas (PRM e IAP) justifica-se pela intenção de relacionar o que as mães dizem fazer com o que acreditam ser importante para a criança, já que em geral as escalas disponíveis na literatura ou avaliam somente o comportamento propriamente dito, ou as crenças sobre as práticas de cuidado.

Inicialmente a escala foi aplicada em um estudo preliminar, em uma amostra de 250 mães. Para o estudo final, a mesma versão da escala foi reaplicada (6 meses depois) em uma amostra de 600 mães. Essa reaplicação teve por objetivo verificar a estabilidade da estrutura fatorial da escala.

\section{Amostras}

Participaram da etapa preliminar 250 mães residentes em cinco contextos diferentes $(50 \mathrm{em}$ Florianópolis, 75 no norte catarinense, 50 no oeste catarinense, 50 na cidade do Rio de Janeiro e 25 em Belém), acima de 18 anos, com, pelo menos, um filho entre 0 e 6 anos na época da coleta de dados. Os locais de coleta dos dados foram selecionados pela facilidade de acesso para os pesquisadores escolhidos. As mães possuíam em média 32,5 anos $(\mathrm{DP}=8,8)$. Com relação à escolaridade, $21 \%$ das mães possuíam o ensino fundamental incompleto, $11 \%$ o fundamental completo, $25 \%$ ensino médio incompleto/completo e $43 \%$ delas estavam cursando, pelo menos, o ensino superior.

Participaram do estudo final 600 mães, 300 residentes em cidades do interior (até $20 \mathrm{mil}$ habitantes) e 300 residentes nas capitais dos seguintes estados: Santa Catarina, São Paulo, Rio de Janeiro, Espírito Santo, Bahia e Pará. Assim, cada estado ficou responsável por acessar 50 mães no interior e 50 mães na capital. As mães deveriam possuir idade mínima de 18 anos e ter pelo menos um filho biológico entre 0 e 6 anos. Quando a mãe possuía mais de um filho, era solicitado que ela respondesse às questões tendo como foco o filho mais novo. Nesta amostra, a idade média foi de 29,5 anos $(\mathrm{DP}=6,5)$. Com relação à escolaridade, $23 \%$ das mães possuíam o ensino fundamental incompleto, $8 \%$ o fundamental completo, $35,5 \%$ ensino médio incompleto/completo e $33,5 \%$ delas estavam cursando, pelo menos, o ensino superior.

\section{Procedimentos de coleta dos dados}

Após o projeto ter sido aprovado pelo Comitê de Ética em Pesquisas com Seres Humanos (protocolos no 166/06 e 239/06), iniciou-se a coleta dos dados. Para garantir a homogeneização dos procedimentos de coleta, um manual foi elaborado pelo grupo de pesquisa contendo informações sobre a preparação do material, condutas durante o encontro com as mães e instruções para a aplicação dos instrumentos.

O recrutamento das participantes ocorreu de formas diferentes em cada contexto. Nas capitais, em geral, as mães foram contatadas por meio de creches públicas e privadas, postos de saúde e indicações das próprias mães participantes. No interior, além das creches, muitas mães foram contatadas em unidades de saúde ou por lideranças presentes na comunidade. Nesse contexto, a coleta de dados geralmente ocorreu em idas ao campo pelas equipes, buscando realizar o maior número de entrevistas de cada vez, já que o deslocamento era difícil e de custo mais alto.

Análise dos dados 
Como se tinha por objetivo estabelecer a validade de construto da escala, foi realizada uma análise fatorial para cada banco de dados separadamente (estudo preliminar e final). Segundo Pasquali e Moura (2003), a análise fatorial tem por finalidade verificar quantos construtos comuns são necessários para explicar as covariâncias dos itens. Assim, pretendia-se verificar se as cinco dimensões dos sistemas parentais eram pertinentes, do ponto de vista empírico, para avaliar as covariâncias dos itens. Duas análises independentes foram realizadas para cada subescala (PRM e IAP), utilizando os seguintes procedimentos:

1) extração dos componentes principais, pela qual se verificou a adequação da matriz quanto aos pressupostos necessários à análise multivariada, utilizando-se o indicador KaiserMeyer-Olkin (KMO) para averiguar a adequação da fatorabilidade. A extração dos componentes principais permitiu também que se definisse o número de fatores, segundo três critérios (Dancey \& Reidy, 2006; Suizzo, 2002): a) eigenvalue maior que 1; b) teste Scree plot de Catell; e c) interpretação teórica;

2) rotação varimax para extrair os fatores, sendo excluídos itens que pesaram em mais de um fator ou itens com carga fatorial inferior ou igual a 0,30. Após essa exclusão, os itens restantes foram sendo submetidos a sucessivas rotações até que nenhum item fosse excluído da matriz;

3) após realizar esses procedimentos em cada subescala, as duas foram comparadas e tornadas idênticas. Para tanto, foram excluídos os itens que apresentaram carga fatorial acima de 0,30 em somente uma subescala e aqueles que pesaram em um fator em uma subescala e em outro fator na outra subescala; e

4) nova rotação varimax em cada subescala, utilizando somente os itens que permaneceram após a comparação das subescalas.

A precisão da escala foi estabelecida pela avaliação da consistência interna de cada fator mediante o cálculo do índice alfa de Cronbach.

\section{Resultados}

Os resultados serão apresentados separadamente para cada estudo (preliminar e final). Em cada um deles serão apresentados os resultados da análise fatorial e, em seguida, os resultados referentes à precisão da escala.

\section{Estudo preliminar}

A extração dos componentes principais indicou que as matrizes (PRM e IAP) eram fatorizáveis ( $\mathrm{KMO}=0,76$ e 0,80 ; respectivamente). Quanto ao número de fatores, segundo os critérios estabelecidos, obtiveram-se os seguintes dados: eigenvalue maior que 1 - (sete fatores para PRM e IAP); Scree plot de Catell - (dois fatores para PRM e quatro fatores para IAP); e critério teórico (cinco fatores para ambas). Ao analisar as matrizes de correlações com cinco fatores (rotação varimax), verificou-se que diversos itens apresentaram cargas fatoriais acima de $0,30 \mathrm{em}$ mais de um fator, o que ocasionaria uma grande perda de itens e, consequentemente, um número pequeno de itens por fator. Assim, realizaram-se rotações com um número cada vez menor de fatores, até que se chegou a uma matriz satisfatória. A matriz com dois fatores, conforme sugerido pelo Scree plot, foi a que melhor se adequou do ponto de vista teórico, e na qual se verificaram cargas fatoriais mais fortes e maior número de itens por fator (tanto na PRM, quanto na IAP).

A subescala PRM, na primeira rotação, explicou 30,4\% da variância. Os itens "abraçar e beijar", "dormir junto na rede ou cama" e "fazer massagem" não apresentaram cargas fatoriais superiores a 0,30 , sendo excluídos da segunda rotação. Todos os 22 itens incluídos nesta última permaneceram na escala e, em conjunto, explicaram $34 \%$ da variância. No primeiro fator foram incluídos itens pertencentes às dimensões teóricas "cuidados primários" e "contato corporal"; já no segundo fator agruparam-se itens pertencentes às dimensões "estimulação corporal", "estimulação por objetos" e "contato face a face". Diante disso, o fator 1 foi denominado "cuidados primários", por integrar itens que dizem respeito à práticas dos cuidadores que garantem a sobrevivência da criança, tais como a higiene, a alimentação e a segurança. Por sua vez, optou-se por nomear o fator 2 de "estimulação", pois inclui práticas que vão além dos cuidados básicos à sobrevivência da criança e estão relacionadas à promoção do desenvolvimento global da mesma.

A subescala IAP necessitou de três rotações para estabilizar seu número de itens. $\mathrm{Na}$ primeira rotação, explicou $33,5 \%$ da variância e três itens não apresentaram cargas fatoriais satisfatórias: "fazer cócegas", "fazer massagem" e "pendurar brinquedos no berço". Quando esses itens foram retirados, a variância explicada subiu 
para 36,3\%; no entanto, mais um item foi excluído ("abraçar e beijar"). Por fim, a última rotação não excluiu mais nenhum item e a escala explicou 37\% da variância. A interpretação teórica para os fatores foi a mesma realizada na subescala PRM, já que no fator 1 agrupou-se a maioria dos itens das dimensões "cuidados primários" e "contato corporal", e no fator 2, itens das dimensões "estimulação corporal", "estimulação por objetos" e "contato face a face".

Ao comparar a estrutura fatorial das duas subescalas de modo a torná-las idênticas, verificou-se que três itens carregaram somente numa subescala e não na outra: "dormir junto na rede ou cama" (somente na IAP), "pendurar brinquedos no berço" (somente na PRM) e "fazer cócegas" (somente na PRM). Além disso, um quarto item carregou em um fator na primeira subescala e em outro fator na segunda ("dar brinquedos"). Todos esses itens foram excluídos de ambas subescalas e os 18 itens restantes foram novamente submetidos a uma rotação. Tanto na PRM quanto na IAP, após a rotação, todos os itens permaneceram na matriz. Somente após esse procedimento foi calculado o alfa de Cronbach para cada fator, em cada subescala. A Tabela 2 apresenta a matriz fatorial após a última rotação em cada subescala, a porcentagem de variância explicada e o alfa de cada fator.

Tabela 2 - Matriz fatorial final das subescalas PRM e IAP no estudo preliminar

\begin{tabular}{|c|c|c|c|c|}
\hline \multirow[t]{2}{*}{ Itens } & \multicolumn{2}{|c|}{ PRM } & \multicolumn{2}{|c|}{ IAP } \\
\hline & Fator 1 & Fator 2 & Fator 1 & Fator 2 \\
\hline Socorrer quando está chorando. & 0,57 & & 0,47 & \\
\hline Alimentar. & 0,49 & & 0,67 & \\
\hline Manter limpa. & 0,51 & & 0,71 & \\
\hline Cuidar para que durma e descanse. & 0,68 & & 0,69 & \\
\hline Não deixar que passe frio ou calor. & 0,57 & & 0,60 & \\
\hline Carregar no colo. & 0,47 & & 0,43 & \\
\hline Ter sempre por perto. & 0,64 & & 0,53 & \\
\hline Tentar evitar que se acidente (cuidados de segurança). & 0,61 & & 0,36 & \\
\hline Deixar livre para correr, nadar, trepar. & & 0,59 & & 0,53 \\
\hline Brincadeiras de luta, de se embolar (corporais). & & 0,44 & & 0,35 \\
\hline Fazer atividades físicas. & & 0,57 & & 0,47 \\
\hline Jogar jogos. & & 0,66 & & 0,57 \\
\hline Ver livrinhos juntos. & & 0,76 & & 0,79 \\
\hline Mostrar coisas interessantes. & & 0,60 & & 0,60 \\
\hline Explicar coisas. & & 0,66 & & 0,70 \\
\hline Ouvir o que tem a dizer. & & 0,72 & & 0,80 \\
\hline Responder a perguntas. & & 0,81 & & 0,71 \\
\hline Ficar frente a frente, olho no olho. & & 0,57 & & 0,74 \\
\hline Eigenvalues & 2,57 & 4,44 & 2,27 & 4,82 \\
\hline Variância explicada (por fator) & $15,4 \%$ & $23,6 \%$ & $16 \%$ & $23,5 \%$ \\
\hline Variância explicada (total) & & $\%$ & & \\
\hline Alfa de Cronbach & 0,70 & 0,83 & 0,68 & 0,80 \\
\hline
\end{tabular}

\section{Estudo final}

A mesma versão da CPPC foi aplicada numa amostra de 600 mães residentes em diferentes regiões do Brasil. Como a amostra, neste estudo, foi maior em número e mais diversificada, esperavam-se algumas diferenças nos resultados da análise fatorial realizada com esses dados em relação aos resultados do estudo preliminar. No entanto, esperava-se que aspectos centrais da estrutura fatorial (como o número de fatores e sua qualidade teórica) se mantivessem de um estudo para o outro, demonstrando assim certa estabilidade da escala.

Novamente, a extração dos componentes principais indicou que as matrizes (PRM e IAP) eram fatorizáveis $(\mathrm{KMO}=0,83$ e 0,85 , respectivamente). O critério eigenvalue maior que 1 indicou a existência de 6 fatores para PRM e IAP. $\mathrm{O}$ Scree plot indicou dois fatores para PRM e três fatores para IAP. Por fim, o critério teórico, 
conforme o modelo de Keller (2007), indicava cinco fatores para ambas subescalas. Visando manter os mesmos procedimentos realizados no estudo preliminar, os itens foram submetidos a sucessivas rotações, partindo de cinco fatores e diminuindo até que se chegasse a uma matriz satisfatória. Igualmente ao estudo anterior, uma matriz com dois fatores foi a que melhor se adequou do ponto de vista teórico e na qual se verificaram cargas fatoriais mais fortes e maior número de itens por fator (tanto na PRM, quanto na IAP)

A subescala PRM necessitou de duas rotações para estabilizar seu número de itens. $\mathrm{Na}$ primeira, explicou $30 \%$ da variância e os itens "abraçar e beijar" e "dormir junto na rede ou cama" não apresentaram cargas fatoriais superiores a 0,30 . Na segunda rotação nenhum item foi excluído e os 23 itens em conjunto explicaram 33\% da variância. Os dois fatores resultantes das rotações incluíram itens teoricamente idênticos aos fatores do estudo preliminar, tendo sido novamente denominados "cuidados primários" e "estimulação".

No estudo preliminar, a subescala IAP necessitou de um número maior de rotações para estabilizar os itens do que a subescala PRM. Isso também aconteceu no estudo final, porém neste foram necessárias quatro rotações. $\mathrm{Na}$ primeira $(32 \%$ da variância explicada), quatro itens não apresentaram cargas fatoriais acima de 0,30: "fazer cócegas", "fazer massagem", "brincadeira de luta, de se embolar" e "dar brinquedos". Quando esses itens foram retirados, a variância explicada subiu para 37\%, todavia, mais um item foi excluído ("dormir junto na rede ou cama"). Ao retirar esse item e realizar nova rotação, a variância subiu para $38 \%$, mas o item "conversar" apresentou carga fatorial acima de 0,30 nos dois fatores e, assim, foi retirado. Por fim, a rotação sem este item resultou numa matriz que explicou $38,5 \%$ da variância, nenhum item a mais tendo sido retirado. A interpretação teórica para os fatores foi a mesma realizada na subescala PRM.

Enquanto no estudo preliminar a comparação das duas subescalas resultou na exclusão de quatro itens, neste estudo, seis itens tiveram de ser excluídos. Todos eles apresentaram cargas fatoriais satisfatórias somente numa subescala e não na outra: "abraçar e beijar" (somente na IAP), "fazer cócegas", "fazer massagem", "brincadeiras de luta, de se embolar", "dar brinquedos" e "conversar" (somente na PRM). Mesmo com a exclusão de um maior número de itens, as subescalas finais ficaram também com 18 itens, os quais foram novamente submetidos a uma rotação. Tanto na PRM quanto na IAP todos os itens permaneceram na matriz e, assim, foi possível calcular o alfa de Cronbach para cada fator, em cada subescala. A tabela 3 apresenta a matriz fatorial após a última rotação em cada subescala, a porcentagem de variância explicada e o alfa de cada fator.

Tabela 3 - Matriz fatorial final das subescalas PRM e IAP no estudo final (continua)

\begin{tabular}{|c|c|c|c|c|}
\hline \multirow[t]{2}{*}{ Itens } & \multicolumn{2}{|c|}{ PRM } & \multicolumn{2}{|c|}{ IAP } \\
\hline & Fator 1 & Fator 2 & Fator 1 & Fator 2 \\
\hline Socorrer quando está chorando. & 0,54 & & 0,55 & \\
\hline Alimentar. & 0,72 & & 0,65 & \\
\hline Manter limpa. & 0,70 & & 0,71 & \\
\hline Cuidar para que durma e descanse. & 0,65 & & 0,68 & \\
\hline Não deixar que passe frio ou calor. & 0,65 & & 0,75 & \\
\hline Carregar no colo. & 0,41 & & 0,34 & \\
\hline Ter sempre por perto. & 0,65 & & 0,52 & \\
\hline Tentar evitar que se acidente (cuidados de segurança). & 0,56 & & 0,51 & \\
\hline Deixar livre para correr, nadar, trepar. & & 0,51 & & 0,44 \\
\hline Fazer atividades físicas. & & 0,52 & & 0,56 \\
\hline Jogar jogos. & & 0,65 & & 0,61 \\
\hline Pendurar brinquedos no berço. & & 0,31 & & 0,39 \\
\hline Ver livrinhos juntos. & & 0,73 & & 0,73 \\
\hline Mostrar coisas interessantes. & & 0,49 & & 0,67 \\
\hline Explicar coisas. & & 0,71 & & 0,73 \\
\hline Ouvir o que tem a dizer. & & 0,71 & & 0,77 \\
\hline Responder a perguntas. & & 0,72 & & 0,74 \\
\hline
\end{tabular}


Tabela 3 - Matriz fatorial final das subescalas PRM e IAP no estudo final (conclusão)

Ficar frente a frente, olho no olho.

Eigenvalues

Variância explicada (por fator)

Variância explicada (total)

Alfa de Cronbach

\begin{tabular}{crrr} 
& 0,48 & & 0,60 \\
\hline 2,93 & 3,81 & 2,35 & 4,80 \\
$17,5 \%$ & $20 \%$ & $17 \%$ & $23 \%$ \\
\multicolumn{2}{c}{$37,5 \%$} & \multicolumn{2}{c}{$40 \%$} \\
0,74 & 0,78 & 0,68 & 0,78 \\
\hline
\end{tabular}

Ao comparar as matrizes resultantes do estudo preliminar e final, destacam-se os seguintes aspectos em comum: 1) número de itens total (18) e número de itens por fator (oito para cuidados primários e 10 para estimulação); 2) dimensão "cuidados primários" composta por itens idênticos; 3) dimensão "estimulação" se manteve enquanto traço latente ao fator 2 ; e 4) variância explicada por cada subescala semelhante. Duas principais diferenças foram observadas entre os resultados de cada estudo: 1) item "brincadeiras de luta, de se embolar" manteve-se na matriz somente no estudo preliminar, e item "pendurar brinquedos no berço" somente no estudo final; e 2) alfa de Cronbach dos fatores resultantes do estudo final inferiores aos do estudo preliminar.

\section{Discussão}

O objetivo deste estudo foi construir e validar uma escala de crenças parentais e práticas de cuidado, a partir de um modelo teórico específico (Modelo de Componentes de Parentalidade, Keller, 2007), sobre o cuidado das crianças na primeira infância. Este foi o primeiro estudo empírico dedicado à avaliação das qualidades psicométricas do instrumento, portanto, não teve pretensões de esgotar as possibilidades de aprimoramento da medida. Diante disso, serão destacados seus aspectos positivos verificados até então, bem como possibilidades de maior discussão e reformulações futuras.

A validação de construto, por meio da análise fatorial, indicou a existência de dois fatores e não cinco, conforme previa o modelo de Keller (2007). Apesar disso, verificou-se que os dois fatores resultantes são passíveis de uma interpretação teórica coerente. $\mathrm{O}$ fator denominado cuidados primários, obtido no presente estudo, englobou os itens construídos teoricamente para esta dimensão, adicionados de itens voltados ao contato corporal. Já o fator estimulação abrangeu itens originalmente elaborados para as dimensões de estimulação corporal, estimulação por objetos e contato face a face.

Com base nesse resultado, contata-se que, apesar de o instrumento ainda não conseguir discriminar os cinco sistemas de cuidado, os mesmos foram agora reagrupados em dois. Enquanto o primeiro fator tem relação com crenças e práticas consideradas essenciais para garantir a sobrevivência da criança na primeira infância, o segundo refere-se a crenças e práticas adicionais utilizadas pelos pais para estimular o desenvolvimento infantil.

Constatou-se ainda que os fatores obtidos possuem relação com outras dimensões de práticas nesta faixa etária, já disponíveis na literatura. Por exemplo, podem-se comparar as dimensões "cuidados primários" e "estimulação" com duas das dimensões verificadas por Suizzo (2002), respectivamente: "apresentação apropriada da criança" e "estimulação e exposição a diferentes estímulos". A definição dessas dimensões é bastante semelhante, sendo as primeiras relacionadas a cuidados básicos e as segundas a estimulações variadas. No entanto, no instrumento de Suizzo (2002) as dimensões são compostas por itens que contemplam práticas voltadas a crianças um pouco maiores (até 3 anos). Em razão disso, a dimensão "apresentação apropriada" tem relação não apenas com cuidados voltados principalmente à sobrevivência da criança, mas também possui itens que contemplam o bom comportamento da mesma em público e sua adequação às expectativas sociais.

No caso específico da dimensão "cuidados primários", que inclui itens referentes à higiene, alimentação, segurança e também ao contato corporal, há disponível na literatura uma dimensão clássica, teoricamente semelhante, construída pelo psicanalista Winnicott (2001). Esse autor afirma que a primeira importante tarefa da mãe, assim que o bebê nasce, trata-se do holding. Essa dimensão tem relação com a capacidade da mãe de identificar-se com o bebê e, dessa forma, dispensar uma porção básica de cuidado, que inclui a rotina completa de cuidados dia e noite e também o bolding (segurar) físico, o carregar a criança. Para esse autor, portanto, os cuidados 
básicos e o contato corporal se agrupam numa única dimensão, assim como no primeiro fator resultante da análise fatorial realizada neste estudo.

Keller (2007), no entanto, ao construir seu modelo teórico, contribui ao caracterizar minuciosamente as práticas parentais na primeira infância, indo além das dimensões cuidado básico $x$ estimulação. Seu modelo foi empiricamente comprovado em diversos estudos transculturais realizados, os quais demonstraram haver diferentes ênfases nas práticas dispensadas às crianças, resultando em dois principais estilos parentais: distal e proximal. Assim, ressalta-se o interesse inicial de construir um instrumento que pudesse caracterizar as diferentes práticas e estilos. Esse propósito não foi atingido com essa versão do instrumento, ou seja, as cinco dimensões não foram discriminadas na análise fatorial.

Num primeiro nível, pode-se pensar que isso não foi possível pela dificuldade de discriminar na forma de itens aspectos bastante sutis do comportamento parental nesta fase, o que resultou em duas dimensões mais robustas, visivelmente distintas. Keller e seus colaboradores em geral utilizam o método observacional para o estudo dos sistemas parentais, assim sendo plausível admitir que um método indireto, como uma escala, dificulte a apreensão dos sistemas. Ainda, admite-se a possibilidade de falhas na construção e avaliação semântica dos itens, tais como: 1) construção de poucos itens para cada dimensão; 2) itens construídos tendo como base somente sistemas observacionais de Keller; 3 ) falta de um estudo mais sistemático de avaliação da dimensionalidade por juízes.

Apesar de não ter se atingido as cinco dimensões dos sistemas de Keller (2007), como já colocado anteriormente, considera-se que os dois fatores obtidos apresentam sentido teoricamente. Além disso, as análises psicométricas realizadas, no geral, demonstraram a validade e precisão da escala. Os índices de alfa de Cronbach dos fatores variaram de 0,68 a 0,83 , sendo o mais baixo deles relacionado ao fator cuidados primários da escala IAP, tanto no estudo preliminar quanto no estudo final. Esse dado indica a possibilidade de melhorias na precisão desta dimensão, mediante um refinamento semântico ou aumento do número de itens para futuros estudos. Além disso, vale ressaltar que os alfa de Cronbach, embora satisfatórios nos dois estudos, foram inferiores no estudo final em relação ao estudo preliminar. Uma possível explicação para esse resultado pode ter relação com o maior número de sujeitos e, consequentemente, uma maior variabilidade nas respostas obtidas no estudo final.

Ainda em relação às análises psicométricas, considera-se que os principais pontos positivos referem-se à porcentagem de variância explicada, chegando a $40 \%$, bem como à estabilidade da estrutura fatorial da escala, a qual se manteve semelhante nos dois estudos realizados, tanto em relação ao número de itens quanto aos valores obtidos nas análises. Houve apenas a alteração de um item entre o estudo psicométrico preliminar e final.

\section{Considerações finais}

A partir dos resultados obtidos, é possível concluir que a escala CPPC trata-se de um instrumento teórico e psicometricamente adequado para utilização em pesquisas que enfoquem o cuidado das crianças na primeira infância. Também na intervenção, de maneira indireta, este instrumento pode ser útil para orientar os profissionais e os próprios cuidadores a respeito das diferentes dimensões constituintes do cuidado. A teoria de Keller (2007) reforça que nenhuma dimensão é mais importante que a outra, mas que cada uma delas possui uma função específica no desenvolvimento da criança.

Como o estudo final foi realizado com um maior número de sujeitos, sugere-se a utilização desta versão da escala em futuras pesquisas. Também a ampliação de outro personagem importante na vida da criança, o pai, que é parte integrante do modelo de parentalidade, poderia trazer informações relevantes para a compreensão de como o cuidado com a criança é avaliado, em termos de crenças e práticas. Outro aspecto que está relacionado com próximos estudos é verificar a relação entre determinadas crenças e práticas de cuidado sobre o desenvolvimento da criança, por meio de um delineamento longitudinal. Tais estudos possivelmente poderão revelar se determinadas práticas são mais adequadas do que outras, tendo como referência o próprio desenvolvimento da criança.

Para um refinamento psicométrico, no sentido de obter as cinco dimensões do modelo de Keller (2007), reconhece-se a importância de estudos que se dediquem ao aprimoramento da validade de conteúdo do instrumento. Por exemplo, entrevistas e observações com os cuidadores podem ser utilizadas como fontes para 
a construção de um maior número de itens por dimensão.

No caso da versão com duas dimensões, podem ser realizados ainda estudos da validade de critério, utilizando instrumentos pareados a fim de verificar a correlação entre as dimensões. Um outro critério possível de ser utilizado seria a própria observação da interação cuidador-criança, em comparação com as respostas obtidas na escala.

\section{Referências}

Benetti, S. P. \& Balbinotti, M. A. (2003). Elaboração e estudo de propriedades psicométricas do Inventário de Práticas Parentais. Psico-USF, 8(2), 103-113.

Costa, F. T., Teixeira, M. A. \& Gomes, W. B. (2000). Responsividade e exigência: duas escalas para avaliar estilos parentais. Psicologia: Reflexão e Crítica, 13(3), 465-473.

Dancey, C. P. \& Reidy, J. (2006). Estatistica sem matemática para a psicologia. Porto Alegre, RS: Artmed.

Gomide, P. I. (2006). Inventário de estilos parentais: modelo teórico, manual de aplicação, apuração $e$ interpretação. Petrópolis: Vozes.

Keller, H. (2002). Development as the interface between biology and culture: A conceptualization of early ontogenetic experiences. Em H. Keller, Y. H. Poortinga \& A. Schöolmerich, Between culture and biology: Perspectives on ontogenetic development (pp. 215235). Cambridge: Cambridge Press University.

Keller, H. (2007). Cultures of infancy. Mahwah, NJ: Erlbaum.

Keller, H., Voelker, S. \& Yovsi, R. D. (2005). Conceptions of parenting in different cultural communities: The case of West African Nso and Northern German women. Social Development, 14(1), 158-180.

Keller, H., Yovsi, R., Borke, J. K., Jensen, H. \& Papaligoura, Z. (2004). Developmental consequences of early parenting experiences: self-recognition and self-regulation in three cultural communities. Child Development, 75(6), $1745-1760$.

Keller, H., Borke, J., Yovsi, R., Lohaus, A. \& Jensen, H. (2005). Cultural orientations and historical changes as predictors of parenting behaviour. International Journal of Behavioral Development, 29(3), 229-237.

Keller, H., Kuensemueller, P., Abels, M., Voelker, S., Yovsi, R., Jensen, H., Papaligoura, Z., Lohaus, A., Rosabal-Coto, M., Kulks, D. \& Mohite, P. (2005). Parenting, culture, and development: A comparative study. San José, CR: Instituto de Investigaciones Psicológicas.

Keller, H., Abels, M., Borke, J., Lamm, B., Lo, W., Su, Y. \& Wang, Y. (2007). Socialization environments of Chinese and Euro-American middle-class babies: Parenting behaviors, verbal discourses and ethnotheories. International Journal of Behavioral Development, 31(3), 210-217.

Martins, G. D. F., Macarini, S. M., Minetto, F. \& Vieira, M. L. (no prelo). Práticas parentais: uma revisão da literatura brasileira.

Pasquali, L. (1998). Princípios de elaboração de escalas psicológicas. Revista de Psiquiatria Clínica, 25(5), 206-213.

Pasquali, L. (2003). Psicometria: teoria dos testes na Psicologia e Educação. Petrópolis: Vozes.

Pasquali, L. \& Moura, C. F. (2003). Atribuição de causalidade ao divórcio. Avaliação Psicológica, 2(1), 1-16.

Schaeffer, E. S. \& Bell, R. Q. (1958). Development of a parental attitude research instrument. Child Development, 29(3), 339-361.

Suizzo, M. A. (2002). French parents' cultural models and childrearing beliefs. International Journal of Behavioral Development, 26, 297-307.

Vieira, M. L., Seidl de Moura, M. L, Lordelo, E., Piccinini, C., Martins, G. D. F., Macarini, S. M., Moncorvo, M., Pontes, F. A., Magalhães, C. M., Salomão, N. \& Rimoli, A. (no prelo). Brazilian mother's beliefs about childrearing practices. Journal of Cross-Cultural Psychology.

Winnicott, D. W. (2001). A família e o desenvolvimento individual. $2^{\mathrm{a}}$ ed. São Paulo: Martins Fontes.

Recebido em março de 2009 Reformulado em setembro de 2009 Aprovado em fevereiro de 2010 
Sobre os autores:

Gabriela Dal Forno Martins é psicóloga formada pela Universidade Federal de Santa Catarina, mestre em Psicologia pelo programa de pós-graduação desta mesma universidade. Tem experiência de pesquisa e extensão na área de Psicologia do Desenvolvimento Infantil, atuando principalmente nos seguintes temas: educação infantil, desenvolvimento, brincadeira, crenças e práticas parentais.

Samira Mafioletti Macarini é psicóloga formada pela Universidade Federal de Santa Catarina (UFSC) e mestre em Psicologia pelo Programa de Pós-Graduação da UFSC. Tem experiência na área de Psicologia do Desenvolvimento, atuando principalmente nos seguintes temas: saúde, educação, desenvolvimento infantil, família, relações parentais e brincadeira na infância.

Mauro Luís Vieira é doutor pela Universidade de São Paulo e fez pós-doutorado na Dalhousie University, Canadá. É professor associado do Departamento de Psicologia e do Programa de Pós-graduação em Psicologia da Universidade Federal de Santa Catarina. Desenvolve pesquisas sobre cuidados parentais e desenvolvimento infantil.

Maria Lúcia Seidl-de-Moura é doutora em Psicologia Cognitiva pela Fundação Getúlio Vargas - RJ e livre-docente pela Universidade Federal do Rio de Janeiro. Fez pós-doutorado na Universidade de São Paulo. Atualmente é professora titular da Universidade do Estado do Rio de Janeiro, desenvolvendo trabalhos de pesquisa na área de interação social e desenvolvimento.

Vera Silvia Raad Bussab possui doutorado em Psicologia Experimental pela Universidade de São Paulo. Atualmente é professora titular da Universidade de São Paulo e participa do Programa de Pós-Graduação em Psicologia Experimental. Tem experiência na área de Psicologia Comparativa, atuando principalmente nos seguintes temas: abordagem etológica, desenvolvimento, apego e creche.

Roberto Moraes Cruz é doutor em Engenharia de Produção pela Universidade Federal de Santa Catarina. Atualmente é professor associado do Departamento de Psicologia e do Programa de Pós-Graduação em Psicologia da Universidade Federal de Santa Catarina. Seus principais temas de interesses são: validação de métodos de medida e avaliação da saúde e de danos psicológicos. 